\title{
Warping Parameters Influence on Warp Yarns Properties: Part 1: Warping Speed and Warp Yarn Tension
}

\section{Dorgham ME*}

Spinning, Weaving and Knitting Dept, Faculty of Applied Arts, Helwan University, Cairo, Egypt

\begin{abstract}
Warping is aimed at preparing the weaver's beam to be set up on the weaving machine. In warping, the yarns are taken from the spools placed on the creel and are wound around the warp beam or roll as per the calculated width of the fabric, an uninterrupted length of hundreds of warp yarns results, all oriented parallel to one another.

This paper reports a study on producing (27) yarn samples by an indirect warping machine (Benninger, BenErgotronic). Samples of yarns were manufactured from continuous raw polyester filaments with three yarn counts $(70,150,300$ denier) under three applied tensions of $(0.15,0.22,0.29 \mathrm{cN} / \mathrm{dtex})$. In addition, three warping speeds $(200,400,600 \mathrm{~m} / \mathrm{min})$ were used. Tensile strength and elongation at break were measured.

The results of measurements of warp yarn count under study for tensile strength and the elongation under the application of the set tension and warping speeds showed optimum tensile strength at warping speed of $400 \mathrm{~m} / \mathrm{min}$, under a tension of $(0.22) \mathrm{cN} / \mathrm{dtex}$. In addition, the optimum elongation percentage was at warping speed of $200 \mathrm{~m} /$ $\mathrm{min}$, under a tension of $(0.22) \mathrm{cN} / \mathrm{dtex}$ for the $(70)$ denier yarns. For (150) and (300) denier yarns, the optimum tensile strength and elongation percentage were at warping speed of $600 \mathrm{~m} / \mathrm{min}$, under a tension of $(0.29) \mathrm{cN} / \mathrm{dtex}$.
\end{abstract}

Keywords: Warping; Yarn; Tension

\section{Introduction}

\section{Warping}

The preparation of warp yarn is more demanding and complicated than that of the filling yarn. Each spot in a warp yarn must undergo several thousand cycles of various tensions applied by the weaving machine. In general terms, warping is transferring many yarns from a creel of single-end packages forming a parallel sheet of yarns wound onto a beam or a section beam. In Figure 1 is shown the Schematic side view of indirect warping process.

Today warping machines can process all kinds of materials including coarse and fine filament and staple yarns [1].

Warping is aimed at preparing the weaver's beam to be set up on the weaving machine depending on the kind of intermediate carrier used, the industrial warping process can be carried out according to two different technologies:

Sectional warping (conical drum or dresser warping).

Beam warping or direct warping (preparatory beam warping) [2].

Modern weaving machines have placed increased demands on warp preparation due to faster weaving speeds and the use of insertion devices other than the shuttle; warp yarn must have uniform properties

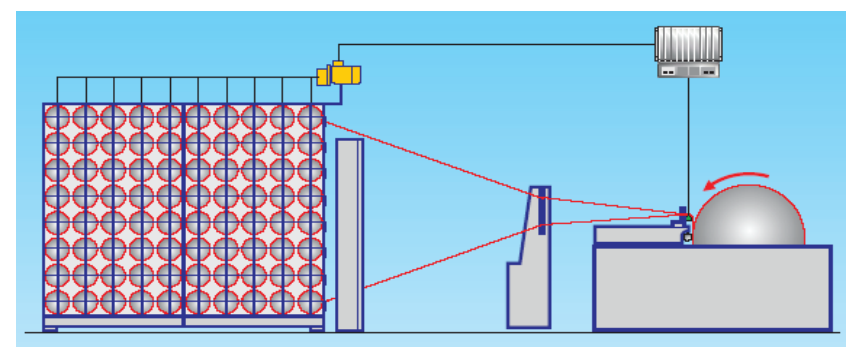

Figure 1: Schematic side view of indirect warping process. with sufficient strength to withstand tension and frictional abrasion during weaving, uniform tension is necessary so that all the warp ends behave the same way.

The tension on the warp yarns is kept relatively low, due to the high inertia of the beam, it is difficult to stop the beam suddenly once an end is broken, however, the beam must be stopped before the broken end reaches the beam [1].

Breaking strength of yarn is the most important physical property of yarn as it represents the main parameter for physical quality control. Breaking strength of yarn depends on many different factors, namely strength of fiber, length of fiber, micronaire, and uniformity [3].

The yarn speed should be kept as constant as possible during warping. In indirect warping a constant speed drive is generally sufficient to provide fairly uniform yarn speed, for some filament yarns variable speed drive is chosen since friction drive would cause problems [1].

\section{Warp yarn tension}

A creel for supplying yarns from a plurality of respective packages to a take-up machine, such as a warp winder, has a support defining respective supply stations carrying the yarn packages, respective tension-sensing deflectors at the stations, and guides for directing the yarns from the respective packages over the respective braking surfaces and around the respective deflectors [4].

*Corresponding author: Dorgham ME, Spinning, Weaving and Knitting Dept, Faculty of Applied Arts, Helwan University, Cairo, Egypt; E-mail: ms.dorgham@yahoo.com

Received March 07, 2013; Accepted May 28, 2013; Published June 03, 2013

Citation: Dorgham ME (2013) Warping Parameters Influence on Warp Yarns Properties: Part 1: Warping Speed and Warp Yarn Tension. J Textile Sci Eng 3: 132. doi:10.4172/2165-8064.1000132

Copyright: (c) 2013 Dorgham ME. This is an open-access article distributed under the terms of the Creative Commons Attribution License, which permits unrestricted use, distribution, and reproduction in any medium, provided the original author and source are credited. 
The number of cones depends on the type of fabric to be produced, the yarns are wound side by side and parallel one another on the beam, if possible with the same tension, the tensioning devices fitted on the creels are designed to obtain this uniform tension, the cone position and their accessibility are two important factors for the operator, the latest creels have yarn tension devices with automatic control and centralized tension variation, these devices allow also to process a wide range of yarns on the same creeling plant, all types of creels can be equipped with air-blowing trolleys to maintain tensioners clean [5].

The thread brake used to control tension during startup of the machine is formed as a pair of parallel and spaced vertical rods extending past each vertical row of yarn supplies. The respective yarns pass between these rods, one of which is movable relative to the other to vary the contact line, that is the length of the piece of filament contacting both rods at one time, and thereby vary drag on the yarn. Such a brake is provided, in the filament travel direction, upstream of the tension sensor, and is set for maximum contact and, therefore, maximum drag at startup to prevent the sensor from responding. Once the yarn is up to speed the drag is normally backed off at the brake since most frictional drag is proportional to speed so that the drag at other points is sufficient to maintain the yarn tension above the response threshold of the lowtension detector [4].

\section{Polyester yarns}

The engineering development of high-speed spinning had important consequences for polyester fiber production. The amorphous undrawn fiber is not very stable. Its structure changes with time, especially if ambient temperatures are high consequently, drawing must take place at a controlled time after wind-up of the undrawn fiber. As wind-up speeds increase, there is competition between the rate of orientation as the filament is elongated and the rate of relaxation of the molecules within the attenuated filament. Above about $3000 \mathrm{~m} / \mathrm{min}$, thread-line orientation is high enough to cause crystallization on cooling; this enables the wind-up of a partially oriented yarn.

(POY), which is stable and suitable for supply to yarn texturing companies, the development of orientation is then completed by drawing due to the difference of input and output speeds on a draw-texturing machine. There is an economic advantage related to production rates in dividing the orientation process in this way. For untextured yarns drawing of POY can be combined with other processes, such as warping. as wind-up speeds are further increased, crystalline increases above about $5000 \mathrm{~m} / \mathrm{min}$, it is possible to produce polyester yarns that can be used in textiles without further processing, though they are more extensible than conventional polyester [6].

In viscoelastic materials the applied force and the resulting deformation both vary sinusoidally with time. For linear viscoelasticity behavior the strain will alternate sinusoidally, but will be out of phase with the tension, one of the important factors in the viscoelasticity behavior of materials is the amplitude of slippage and movement of their component over each other owing to tensile tension, when a filament yarn is subjected to a tensile load.

It has been proved that the tensile tension of warp yarns is independent of geometry and fiber structure, the mechanical properties of filament warp yarns under load depend on internal factors such as material quality evenness, twist and external factors such as time [7].

\section{The relationship between warp yarn and fabric properties}

Warp yarns in their different applications during weaving processes are often required to support loads, either in a static manner (simple tensile) or in a dynamic one ( fatigue). This effect that may cause decay or even failure to meet the mechanical properties, after repeated application of tension or strain which occurs usually under a specified hertz or frequency is called fatigue.

It should also be noted that the filament warp yarns behavior under weaving conditions can be useful for optimum weaving efficiency and fabric quality [7].

The functional performance of any fabric in general depends on the natural and mechanical properties of the elements that make up this fabric, and the structural composition of it. Specifically tensile strength and elongation percentage play a key role in determining the suitability of the fabric to the proposed function.

Several studies have shown that the increase in tensile strength and elongation percentage of yarns lead to the increase of the tensile strength and elongation percentage of fabrics made by those yarns. The problem was in mathematically predicting the exact values of those two properties based on the sole information of the tensile strength and elongation percentage of the yarns used in making those fabrics. This can be attributed to the influence of the fabric structure which influences the total tensile strength and elongation percentage of the produced fabric [8].

\section{The Experimental Work}

This paper reports a study on producing (27) polyester yarn samples by an indirect warping machine (Benninger, Ben-Ergotronic, Switzerland) [9].that carry an extension equipment for organize the applied tension $\mathrm{cN} / \mathrm{dtex}$ through controlling air pressure on the yarn creel plates

Samples of yarns were manufactured from continuous raw polyester filaments with three counts $(70,150,300$ denier $)$ under three applied yarn tensions $(0.15,0.22,0.29 \mathrm{cN} / \mathrm{dtex})$. In addition, three warping speeds $(200,400,600 \mathrm{~m} / \mathrm{min})$ were used. Tensile strength test and percentage elongation of the yarn after yarn warping were used to measure the rate of change in the physical properties of the yarn to reach the best operating conditions suitable for these kinds of threads, Figure 2 shows the Benninger warping machine.

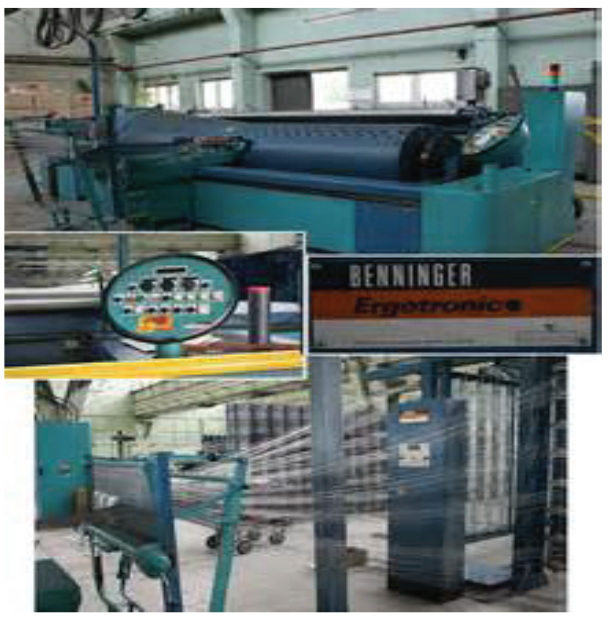

Figure 2: Benninger warping machine showed the attached applied tension equipment. 


\section{Tests applied to samples under study}

Yarn samples under study were tested for tensile strength and elongation at break using 48-02 Universal Tester 3KN-CT (five reading for each sample) according to ASTM -D 2256-02 [10], to evaluate the produced fabrics properties.

The following are the specification of samples under study and the testing results shown in Table 1.

\section{Result and Discussion}

\section{Tensile strength $(\mathrm{Kg})$}

Applied yarn tension force effect: From results listed in (Tables 1-5) and (Figures 3-5) the significant role played by control devices located on the threads during warping operations during the withdrawal from the warping machine creel is clear on the properties of the warp yarns and their effectiveness to resist the textile weaving processes through

\begin{tabular}{|c|c|c|c|c|c|}
\hline \multirow{2}{*}{$\begin{array}{c}\text { Sample } \\
\text { No. }\end{array}$} & \multicolumn{3}{|c|}{ Specifications } & \multirow{2}{*}{$\begin{array}{l}\text { Tensile } \\
\text { strength } \\
\text { (Kg) }\end{array}$} & \multirow{2}{*}{$\begin{array}{c}\text { Elongation } \\
(\%)\end{array}$} \\
\hline & $\begin{array}{c}\text { Yarn count } \\
\text { denier }\end{array}$ & $\begin{array}{l}\text { Applied } \\
\text { tension } \\
\text { cN/dtex }\end{array}$ & $\begin{array}{l}\text { Warping } \\
\text { speed } \\
\mathrm{m} / \mathrm{min}\end{array}$ & & \\
\hline 1 & \multirow{9}{*}{70} & \multirow{3}{*}{0.15} & 200 & $0.85 \pm 0.04$ & $19.6 \pm 1.8$ \\
\hline 2 & & & 400 & $0.92 \pm 0.05$ & $18.4 \pm 1.3$ \\
\hline 3 & & & 600 & $0.82 \pm 0.04$ & $18.4 \pm 1.9$ \\
\hline 4 & & \multirow{3}{*}{0.22} & 200 & $0.93 \pm 0.06$ & $22.4 \pm 2$ \\
\hline 5 & & & 400 & $1.01 \pm 0.11$ & $21.3 \pm 1.9$ \\
\hline 6 & & & 600 & $0.91 \pm 0.07$ & $21.6 \pm 2$ \\
\hline 7 & & \multirow{3}{*}{0.29} & 200 & $0.9 \pm 0.05$ & $18.4 \pm 1.9$ \\
\hline 8 & & & 400 & $0.89 \pm 0.07$ & $18.1 \pm 2$ \\
\hline 9 & & & 600 & $0.78 \pm 0.05$ & $17.4 \pm 1.8$ \\
\hline
\end{tabular}

Table 1: Specifications and results for the produced samples (1-9).

\begin{tabular}{|c|c|c|c|c|c|}
\hline \multirow{2}{*}{$\begin{array}{c}\text { Sample } \\
\text { No. }\end{array}$} & \multicolumn{3}{|c|}{ Specifications } & \multirow{2}{*}{$\begin{array}{l}\text { Tensile } \\
\text { strength } \\
(\mathrm{Kg})\end{array}$} & \multirow{2}{*}{$\begin{array}{c}\text { Elongation } \\
(\%)\end{array}$} \\
\hline & $\begin{array}{c}\text { Yarn count } \\
\text { denier }\end{array}$ & $\begin{array}{l}\text { Applied } \\
\text { tension } \\
\text { cN/dtex }\end{array}$ & $\begin{array}{l}\text { Warping } \\
\text { speed } \\
\mathrm{m} / \mathrm{min}\end{array}$ & & \\
\hline 10 & \multirow{9}{*}{150} & \multirow{3}{*}{0.15} & 200 & $1.1 \pm 0.15$ & $25.7 \pm 2$ \\
\hline 11 & & & 400 & $1.25 \pm 0.17$ & $28.5 \pm 1.7$ \\
\hline 12 & & & 600 & $1.33 \pm 0.07$ & $29.2 \pm 1.9$ \\
\hline 13 & & \multirow{3}{*}{0.22} & 200 & $1.36 \pm 0.09$ & $27 \pm 2$ \\
\hline 14 & & & 400 & $1.37 \pm 0.12$ & $27.8 \pm 1.9$ \\
\hline 15 & & & 600 & $1.57 \pm 0.11$ & $29.1 \pm 1.6$ \\
\hline 16 & & \multirow{3}{*}{0.29} & 200 & $1.59 \pm 0.12$ & $27.7 \pm 2$ \\
\hline 17 & & & 400 & $1.42 \pm 0.13$ & $28.2 \pm 1.8$ \\
\hline 18 & & & 600 & $1.76 \pm 0.16$ & $28.6 \pm 2$ \\
\hline
\end{tabular}

Table 2: Specifications and results for the produced samples (10-18).

\begin{tabular}{|c|c|c|c|c|c|}
\hline \multirow{2}{*}{$\begin{array}{c}\text { Sample } \\
\text { No. }\end{array}$} & \multicolumn{3}{|c|}{ Specifications } & \multirow{2}{*}{$\begin{array}{l}\text { Tensile } \\
\text { strength } \\
\text { (Kg) }\end{array}$} & \multirow{2}{*}{$\begin{array}{c}\text { Elongation } \\
(\%)\end{array}$} \\
\hline & $\begin{array}{c}\text { Yarn count } \\
\text { denier }\end{array}$ & $\begin{array}{l}\text { Applied } \\
\text { tension } \\
\text { cN/dtex }\end{array}$ & $\begin{array}{l}\text { Warping } \\
\text { speed } \\
\mathrm{m} / \mathrm{min}\end{array}$ & & \\
\hline 19 & \multirow{9}{*}{300} & \multirow{3}{*}{0.15} & 200 & $1.97 \pm 0.17$ & $31.9 \pm 2.2$ \\
\hline 20 & & & 400 & $2.01 \pm 0.14$ & $32.1 \pm 2.2$ \\
\hline 21 & & & 600 & $2.05 \pm 0.16$ & $32.8 \pm 2.1$ \\
\hline 22 & & \multirow{3}{*}{0.22} & 200 & $2.07 \pm 0.17$ & $34.8 \pm 1.9$ \\
\hline 23 & & & 400 & $2.1 \pm 0.14$ & $33.1 \pm 2.1$ \\
\hline 24 & & & 600 & $1.95 \pm 0.11$ & $33.4 \pm 1.9$ \\
\hline 25 & & \multirow{3}{*}{0.29} & 200 & $2.08 \pm 0.18$ & $35.2 \pm 2$ \\
\hline 26 & & & 400 & $2.14 \pm 0.20$ & $34.7 \pm 1.9$ \\
\hline 27 & & & 600 & $2.25 \pm 0.16$ & $37.6 \pm 2$ \\
\hline
\end{tabular}

Table 3: Specifications and results for the produced samples (19-27).

\begin{tabular}{|c|c|c|c|c|c|c|}
\hline Source & DF & Seq SS & Adj SS & Adj MS & $\mathbf{F}$ & P. Value \\
\hline YARN COUNT & 2 & 31.4346 & 31.4346 & 15.7173 & 986.44 & 0.000 \\
\hline APPLIED TENSION & 2 & 0.6406 & 0.6406 & 0.3203 & 20.10 & 0.000 \\
\hline WARPING SPEED & 2 & 0.0865 & 0.0865 & 0.0433 & 2.72 & 0.071 \\
\hline $\begin{array}{c}\text { YARN COUNT* } \\
\text { APPLIED TENSION }\end{array}$ & 4 & 0.5933 & 0.5933 & 0.1483 & 9.31 & 0.000 \\
\hline $\begin{array}{l}\text { YARN COUNT* } \\
\text { WARPING SPEED }\end{array}$ & 4 & 0.4303 & 0.4303 & 0.1076 & 6.75 & 0.000 \\
\hline $\begin{array}{l}\text { APPLIED TENSION* } \\
\text { WARPING SPEED }\end{array}$ & 4 & 0.1020 & 0.1020 & 0.0255 & 1.60 & 0.179 \\
\hline $\begin{array}{l}\text { YARN COUNT* } \\
\text { APPLIED TENSION* } \\
\text { WARPING SPEED }\end{array}$ & 8 & 0.1907 & 0.1907 & 0.0238 & 1.50 & 0.167 \\
\hline Error & 108 & 1.7208 & 1.7208 & 0.0159 & & \\
\hline Total & 134 & 35.1988 & & & & \\
\hline$S=0.126227$ & \multicolumn{3}{|c|}{ R-Sq $=95.11 \%$} & \multicolumn{3}{|c|}{ R-Sq $(\operatorname{adj})=93.93 \%$} \\
\hline
\end{tabular}

Table 4: Analysis of Variance for Tensile strength (Kg), using Adjusted SS for Tests.

\begin{tabular}{|c|c|c|c|c|c|c|}
\hline Source & DF & Seq SS & Adj SS & Adj MS & $\mathbf{F}$ & P. Value \\
\hline YARN COUNT & 2 & 4718.68 & 4718.68 & 2359.34 & 637.30 & 0.000 \\
\hline APPLIED TENSION & 2 & 54.52 & 54.52 & 27.26 & 7.36 & 0.001 \\
\hline WARPING SPEED & 2 & 11.76 & 11.76 & 5.88 & 1.59 & 0.209 \\
\hline $\begin{array}{c}\text { YARN COUNT* } \\
\text { APPLIED TENSION }\end{array}$ & 4 & 163.30 & 163.30 & 40.82 & 11.03 & 0.000 \\
\hline $\begin{array}{l}\text { YARN COUNT* } \\
\text { WARPING SPEED }\end{array}$ & 4 & 47.72 & 47.72 & 11.93 & 3.22 & 0.015 \\
\hline $\begin{array}{l}\text { APPLIED TENSION* } \\
\text { WARPING SPEED }\end{array}$ & 4 & 6.63 & 6.63 & 1.66 & 0.45 & 0.774 \\
\hline $\begin{array}{l}\text { YARN COUNT* } \\
\text { APPLIED TENSION* } \\
\text { WARPING SPEED }\end{array}$ & 8 & 27.81 & 27.81 & 3.48 & 0.94 & 0.488 \\
\hline Error & 108 & 399.83 & 399.83 & 3.70 & & \\
\hline Total & 134 & 5430.25 & & & & \\
\hline$S=.92409$ & \multicolumn{3}{|c|}{ R-Sq $=92.64 \%$} & \multicolumn{3}{|c|}{$($ adj $)=90.86 \%$} \\
\hline
\end{tabular}

Table 5: Analysis of Variance for Elongation (\%), using Adjusted SS for Tests.

the change in the internal tension forces of the threads after warping process. By observing the results for the (70) denier warp yarns shown in respective diagrams, a clear difference can be found in the values of readings of tensile strength of the yarns produced. As yarns recorded the highest values of the readings under the tension of $(0.22) \mathrm{cN} / \mathrm{dtex}$ as shown in Figure 4, followed by yarns produced under $(0.1 \mathrm{f} 5) \mathrm{cN} /$ dtex tension as shown in Figure 3, the lowest value was achieved by yarns produced under (0.29) cN/dtex tension as shown in Figure 5, this was attributed to the low thickness and count of the yarns, which was unsuitable for the tension used during the warping process. By studying the tension results of (150) denier, it was noted that the highest values of readings for the tensile strength recorded for the $(0.29) \mathrm{cN} / \mathrm{dtex}$ as in Figure 5. As an optimum result, followed by the $(0.22) \mathrm{cN} / \mathrm{dtex}$ and then the results under tension $(0.15) \mathrm{cN} / \mathrm{dtex}$ as shown in Figures 3 and 4. Moreover, the tensile strength results for (300) denier yarns scored the optimum value at $(0.29) \mathrm{cN} / \mathrm{dtex}$ followed by those under $(0.22) \mathrm{cN} /$ dtex tension and finally yarns under $(0.15) \mathrm{cN} / \mathrm{dtex}$ tension recorded the lowest readings. From the aforementioned review, it was clear that the yarns were affected by the external tension applied on them. Moreover, it was found that the highest tensile strength in the subs subsequent weaving processes after warping was achieved by yarns withdrawal from the warping machine creel under $(0.29) \mathrm{cN} / \mathrm{dtex}$, especially for yarns $(150,300)$ denier. This may be attributed to the straightening of the yarns during the process. This was aided by the reorganization of the polymer chains in the longitudinal direction of the fiber and the reorientation of the individual fibers in the longitudinal direction of 


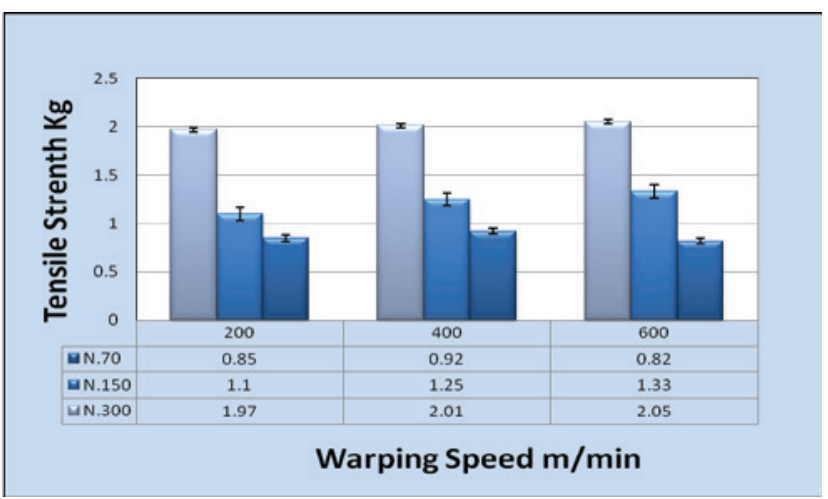

Figure 3: The relationship between tensile strength and warping speed at constant of applied yarn tension (0.15) cN/dtex.

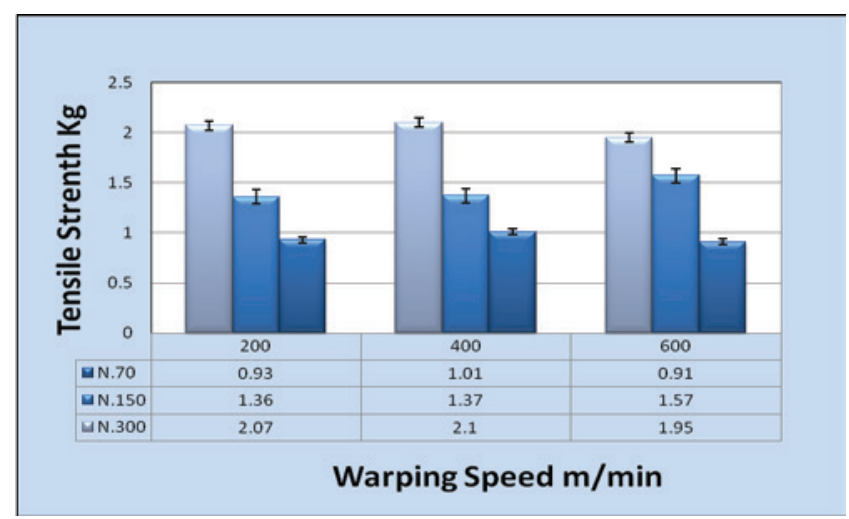

Figure 4: The relationship between tensile strength and warping speed at constant of applied yarn tension $(0.22) \mathrm{cN} / \mathrm{dtex}$.

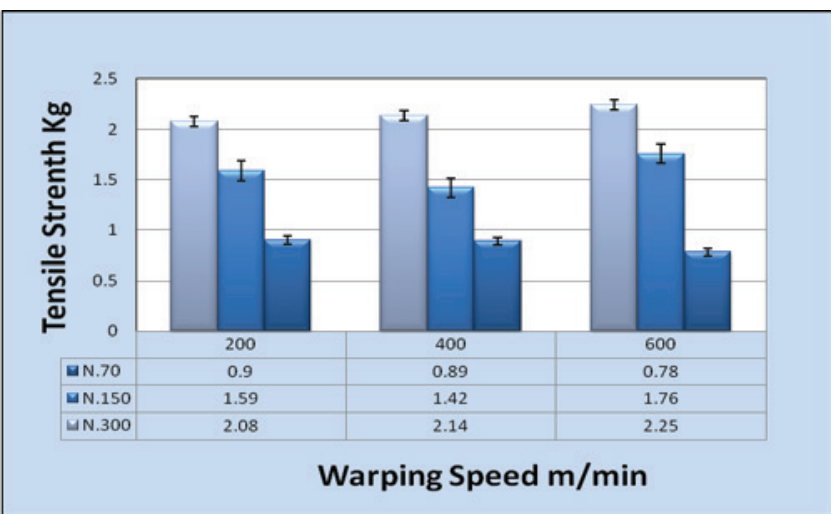

Figure 5: The relationship between tensile strength and warping speed at constant of applied yarn tension (0.29) cN/dtex

the yarns. This combined enables the yarns to resist the external forces faced by the yarns under operation. In addition, the applied tension on the yarns prevents balloon, buttonholes and folds formation affecting the surface appearance and efficiency of filaments during warping which in turn improves the uniformity of yarns and its resistance to external forces acting on them. For (70) denier yarns, the decrease in yarn diameter and the subsequent decrease in number of fibers in cross section compared to the other yarns in the study has led to the decreased capacity to withstand external acting tensions and not being able to withstand tension of $(0.29) \mathrm{cN} / \mathrm{dtex}$ and therefore the optimum readings were achieved at applied tensions of $(0.22)$ and $(0.15) \mathrm{cN} / \mathrm{dtex}$.

\section{Warping speed effect}

Results from figures and tables showed significant effect of warping speed during the warping process on the results of the tensile strength of produced different yarns count. Yarns of (70) denier showed the highest tensile strength results at a speed of $400 \mathrm{~m} / \mathrm{min}$ at a constant tension of $(0.15) \mathrm{cN} / \mathrm{dtex}$, followed by yarns warped at $200 \mathrm{~m} / \mathrm{min}$ and finally those warped at $600 \mathrm{~m} / \mathrm{min}$. Similar results were achieved by yarns produced under tension of $(0.22) \mathrm{cN} / \mathrm{dtex}$ at a warping speed of $400 \mathrm{~m} / \mathrm{min}$, followed by yarns warped at 200 and then $600 \mathrm{~m} / \mathrm{min}$. For those produced at $(0.29) \mathrm{cN} / \mathrm{dtex}$, the readings were different where the importance is shown by decreasing the warping speed to $200 \mathrm{~m} /$ min was quite obvious in relation to the yarn thickness and in keeping the interrelationship between tension and thickness and warping speed according to the physical properties of the yarn material. The warping speed of $200 \mathrm{~m} / \mathrm{min}$ achieved the highest results of yarns tensile strength. Tensile strength was decreased for speeds of 400 and $600 \mathrm{~m} /$ min. For (70) denier yarns under different tensiones, the highest tensile strength was at warping speeds of $400 \mathrm{~m} / \mathrm{min}$ as an optimum condition.

For (150) denier yarns, speeds of $600 \mathrm{~m} / \mathrm{min}$ showed the highest tensile strength at a constant tension of $(0.15) \mathrm{cN} / \mathrm{dtex}$, followed by the tensile results at 400 and $200 \mathrm{~m} / \mathrm{min}$. Also, similar results were achieved for yarns produced under a tension of $(0.22) \mathrm{cN} / \mathrm{dtex}$. On the contrary, results for yarns produced under $(0.29) \mathrm{cN} / \mathrm{dtex}$ were different as the highest tensile result was achieved at speeds of 600,200 and $400 \mathrm{~m} /$ min respectively. Accordingly, it is obvious the preference of using those yarns under high warping speeds and its suitability for all tension situations.

The results were not greatly changed for (300) denier yarns. As the highest tensile strength was at warping speeds of $600 \mathrm{~m} / \mathrm{min}$ at a constant tension of $(0.15) \mathrm{cN} / \mathrm{dtex}$, followed by tensile strength results at warping speeds of 400 and $200 \mathrm{~m} / \mathrm{min}$ respectively. Similar results were observed at for yarns produced at $(0.29) \mathrm{cN} / \mathrm{dtex}$ for the same set of yarns with the exception of the increase in the total results value when operated under $(0.29) \mathrm{cN} / \mathrm{dtex}$. As for the highest values for yarns produced under $(0.22) \mathrm{cN} / \mathrm{dtex}$ the results were different where the highest tensile strength value was achieved at $(400,200)$ and $600 \mathrm{~m} / \mathrm{min}$ respectively. This could be attributed to external operational conditions which affected the yarns results under this tension but this does not affect the suitability of producing those yarns under this high tension and warping speed.

\section{Elongation (\%)}

Applied yarn tension force effect: Analyzing elongation results listed in (Tables 1-5) and a depicted graph 6, 7, and 8 shows an inverse relationship between warping speed and yarn elongation. This relationship is not absolute, but in total indicates the impact of the withdrawal speed of yarns during warping on the values of yarn elongation, especially as the yarns used are made of polyester continues filaments, which are characterized by their flexibility and ability to elongate. By perusing the results of (70) denier yarns, the highest elongation percentage was when yarns were wrapped under a tension of $(0.22) \mathrm{cN} / \mathrm{dtex}$, followed elongation values for yarns wrapped under a tension of $(0.15) \mathrm{cN} / \mathrm{dtex}$. The lowest value for elongation percentage was for yarns wrapped under a tension of $(0.29) \mathrm{cN} / \mathrm{dtex}$. This may be attributed for the prominent effect when placed under high tension, 


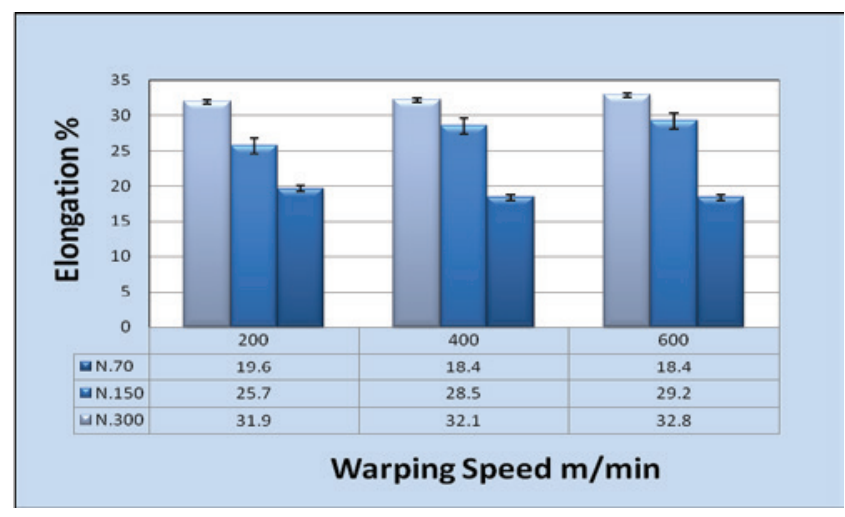

Figure 6: The relationship between elongation and warping speed at constant of applied yarn tension (0.15) cN/dtex.

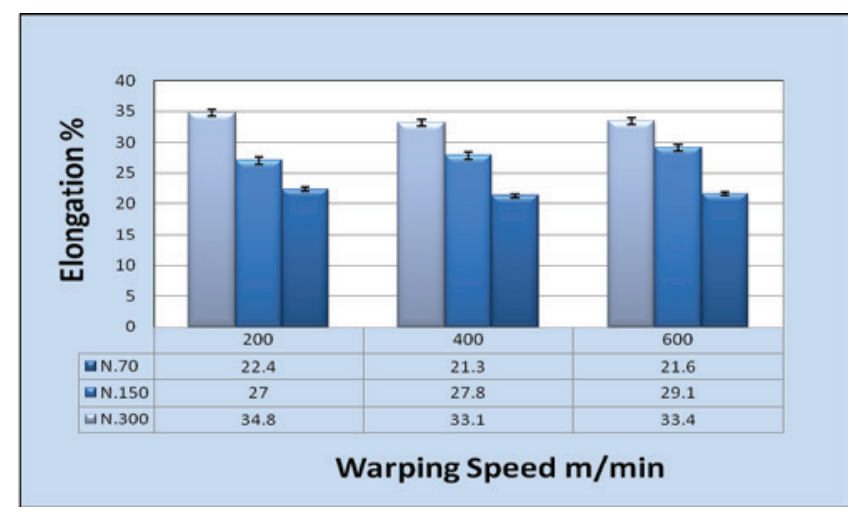

Figure 7: The relationship between elongation and warping speed at constant of applied yarn tension $(0.22) \mathrm{cN} / \mathrm{dtex}$.

especially as the used yarns have small thickness, which in turn affects the internal forces of the yarns and accelerates the breakage process during elongation. A for (150) denier yarns, highest elongation values were for yarns tension under $(0.29) \mathrm{cN} / \mathrm{dtex}$, followed by elongation values under $(0.22) \mathrm{cN} / \mathrm{dtex}$ and finally the lowest value was for yarns under $(0.15) \mathrm{cN} /$ dtex due to the increased diameter of those yarns and its ability to withstand tensions.

From the previous demonstration the role played by yarn count, and its ability to withstand external tensions during operation was demonstrated in the results of (150) and (300) denier yarns. On contrary, (70) denier yarns achieved lower elongation values due to its lower diameter and its reduced ability to withstand external forces.

\section{Warping speed effect}

By studying the elongation percentage listed and depicted in relevant tables and graphs, the effect of different warping speeds is obvious. Results of (70) denier as shown in Table 1, shows that best elongation value was at $400 \mathrm{~m} / \mathrm{min}$, followed by $200 \mathrm{~m} / \mathrm{min}$, and finally the lowest value was at $600 \mathrm{~m} / \mathrm{min}$. This was attributed to the increasing effect of warping speed on the yarns. By changing the tension to $(0.22)$ $\mathrm{cN} / \mathrm{dtex}$ as shown in Figure 7 It was observed that in general the elongation results were better, but the highest elongation values were at $(200,600$, and 600$) \mathrm{m} / \mathrm{min}$ respectively. The results decreased again under a tension of $(0.29) \mathrm{cN} / \mathrm{dtex}$ where the lowest results were scored. Under the aforementioned tension the highest elongation was achieved at operational speeds of 200 and $400 \mathrm{~m} / \mathrm{min}$. And from the results it was clear the suitability of operating those yarns under the low speeds of (400:200) $\mathrm{m} / \mathrm{min}$. As for elongation results for (150) denier yarns as shown in Figure7 The highest results were achieved at $(600,400$ and 200) $\mathrm{m} / \mathrm{min}$ respectively. The results was not changed largely under operational tension of ( 0.22 and 0.29$) \mathrm{cN} / \mathrm{dtex}$ as shown in Figures 7 and 8 . The best results were achieved under a tension of $(0.29) \mathrm{cN} /$ dtex. As for elongation results of (300) denier yarns, the best results was achieved at operational speeds at $600 \mathrm{~m} / \mathrm{min}$ as shown in Figure 7, followed by 400 and $200 \mathrm{~m} / \mathrm{min}$ respectively as shown in Figure 6 as for Figure 7 the highest values were at $(200,600$, and 400$) \mathrm{m} / \mathrm{min}$ respectively. And here the relationship of increasing the applied force on the yarns and warping speed and its influence on the results of the elongation percentage plays a role, but this relation is not constant. This was shown in Figure 8 Where the highest results under the highest applied tension of $(0.29) \mathrm{cN} / \mathrm{dtex}$ was at warping speeds of $(600,200$, and 400$) \mathrm{m} / \mathrm{min}$ respectively. As for operational conditions of (300) denier, the best conditions would be a tension of $(0.29) \mathrm{cN} / \mathrm{dtex}$ and warping speed of $600 \mathrm{~m} / \mathrm{min}$.

\section{Conclusion}

There were only significant differences among the levels of count and applied tension at (0.01) probability levels for both tensile strength and elongation, while the interaction effects between count at one side and each of applied tension and warping speed at the other side were significant at (0.01) probability levels for the two aimed characters. On the other hand the remainder sources of variations were no significant. Table 6 shows the optimum yarn operational settings.

Based on the aforementioned operational conditions of synthetic fibers under study and the previous discussion, the optimum machine settings can be summarized in the following:

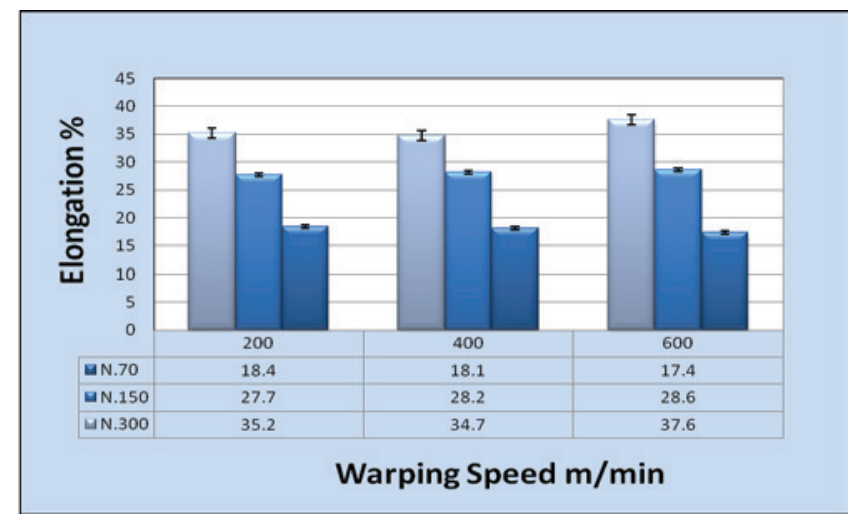

Figure 8: The relationship between elongation and warping speed at constant of applied yarn tension (0.29) cN/dtex.

\begin{tabular}{|c|c|c|c|c|c|c|}
\hline $\begin{array}{c}\text { Yarn } \\
\text { count } \\
\text { Denier }\end{array}$ & \multicolumn{2}{|c|}{$\begin{array}{c}\text { Tensile strength } \\
\text { (Kg) }\end{array}$} & \multicolumn{2}{c|}{$\begin{array}{c}\text { Elongation } \\
\text { (\%) }\end{array}$} & \multicolumn{2}{c|}{ Average } \\
\cline { 2 - 7 } & $\begin{array}{c}\text { Applied } \\
\text { tension } \\
\text { cN/dtex }\end{array}$ & $\begin{array}{c}\text { Warping } \\
\text { speed } \\
\text { m/min }\end{array}$ & $\begin{array}{c}\text { Applied } \\
\text { tension } \\
\text { cN/dtex }\end{array}$ & $\begin{array}{c}\text { Warping } \\
\text { speed } \\
\text { m/min }\end{array}$ & $\begin{array}{c}\text { Applied } \\
\text { tension } \\
\text { cN/dtex }\end{array}$ & $\begin{array}{c}\text { Warping } \\
\text { speed } \\
\text { m/min }\end{array}$ \\
\hline 70 & 0.22 & 400 & 0.22 & 200 & 0.22 & $200-400$ \\
\hline 150 & 0.29 & 600 & 0.29 & 600 & 0.29 & 600 \\
\hline 300 & 0.29 & 600 & 0.29 & 600 & 0.29 & 600 \\
\hline
\end{tabular}

Table 6: Optimum yarn operational settings. 
Citation: Dorgham ME (2013) Warping Parameters Influence on Warp Yarns Properties: Part 1: Warping Speed and Warp Yarn Tension. J Textile Sci Eng 3: 132. doi:10.4172/2165-8064.1000132

Page 6 of 6

\section{0 denier yarns}

Optimum tensile strength was at warping speed of $400 \mathrm{~m} / \mathrm{min}$, under tension of $0.22 \mathrm{cN} / \mathrm{dtex}$

Optimum elongation percentage was at warping speed of $200 \mathrm{~m} /$ min, under tension of $0.22 \mathrm{cN} / \mathrm{dtex}$

\section{0 and 300 denier yarns}

Optimum tensile strength was at warping speed of $600 \mathrm{~m} / \mathrm{min}$, under tension of $0.29 \mathrm{cN} / \mathrm{dtex}$

Optimum elongation percentage was at warping speed of $600 \mathrm{~m} /$ min, under tension of $0.29 \mathrm{cN} / \mathrm{dtex}$

\section{References}

1. Adanur S (2001) Handbook of Weaving. Technomic Publishing Co, Lancaster, Pennsylvania, USA.

2. Giovanni C, Salvatore M, Giuseppe S, Ivo Matteo S (2000) Weaving Reference Book of Textile Technologies. Italian Association of Textile Machinery Producers Milano, Italy.
3. Dayik M (2009) Prediction of yarn properties using evaluation programming Textile Research Journal 79: 963-972.

4. Kohlen, Karl-Heinz (1987) Creel for warping machine. U.S patent, no.4664335

5. ACIMIT (2000) The Italian textile machinery industry, today: characteristics, raw materials, technologies, Published for technical high-schools.

6. Morton WEJ, Hearls WS (2008) Physical properties of textile fibres. Fourth edition, Woodhead Publishing Limited, Cambridge, England.

7. Deopura BL, Alagirusamy R, Joshi M, Gupta B (2008) Polyesters and polyamides. Woodhead Publishing Limited, Cambridge, England.

8. Nosraty H, Ali AA, Jamshidi M (2009) Fatigue behavior of filament warp yarns under cyclic loads during weaving process. Textile Research Journal 79: 154 165

9. Ibrahim, SO (2010) An analytical \& comparative study for tensile strength and elongation between cotton yarns and fabrics which woven from it. Sciences \& Arts .Research Studies.

10. ASTM-D 2256-02 Standard Test Method for Tensile Properties of Yarn by the Single-Strand Method. 